\title{
CEMENT PASTE CONTAINING MICRONIZED RECYCLED CONCRETE - INFLUENCE OF HARDENING ACCELERATORS ON THE MODULUS OF ELASTICITY
}

\author{
JAKub ĎUREJE*，ZDENĚK ProšEK \\ Czech Technical University in Prague, Faculty of Civil Engineering, Department of Mechanics, Thákurova 7, \\ 16629 Prague 6, Czech Republic \\ * corresponding author: jakub.dureje@fsv.cvut.cz
}

\begin{abstract}
The article deals with the selection of a suitable hardening accelerator for cement composite material for mass production of masonry blocks. The blocks contain cement and finely ground recycled concrete in ratio 1:1. Three different hardening accelerators in different quantity were tested for possibility of fast removing formwork. The dynamic modulus of elasticity was measured by non-destructive resonance method to determine the initial strengths. The modulus of elasticity was measured 7 and 12 hours after sample production to determine the increase in initial strength. Subsequently, the modulus of elasticity was measured at 1, 7, 14, 21 and 28 days after production of the test specimens. The resulting moduli of elasticity were compared with reference samples.
\end{abstract}

KEYWORDS: Finely ground concrete, hardening accelerator, recycled concrete, recycled masonry blocks.

\section{INTRODUCTION}

Old waste concrete from damaged or destroyed structures has the risky properties because of different attributes and inhomogeneity of this waste, which are caused by the presence of other materials from building demolitions (bricks, wood, glass, reinforcement, etc.). The quality of the recycled concrete thus depends on the degree and diligence of the recycling of the recycled concrete. Unfortunately, waste concrete sorting is negatively reflected in the price of this raw material. Recycled concrete is most often used as a base layer under the roadway. For the common application, a recycle fraction greater than $1 \mathrm{~mm}$ is used, the use of finer fractions brings many complications and additional financial costs [1, 2].

The paper deals with the measurement of the dynamic modulus of elasticity of samples from the early hardening phase up to the age of 28 days. The samples contain cement and recycled concrete in weight ratio 1:1, mixing water and various hardening accelerators.

Recycled concrete containing the finest fraction $0 / 1 \mathrm{~mm}$ was used, this material was gently ground by high speed mill. The use of this fine fraction, which today has almost no use, is an advantage of this material, because fine recycled concrete fractions are often stored in landfills as waste material, it follows that using of this material is cost effective and environmental friendly. The finely ground recycled concrete is used in cement composite as a filler with certain binding properties [3].

This cementitious composite will be lightened and will be used to produce thermal insulation perimeter blocks. Due to the possibility of mass production of blocks on the production line, a rapid increase in initial strength is needed because of the blocks formwork can be removed and used for the production of other blocks in the shortest possible time. For this reason, different hardening accelerators have been added to the mixtures, and the modulus of elasticity has been measured since the early hardening phase 4 .

From previous experiments it has been shown that with increasing percentage of recycled concrete in the mixture there is a decrease in compressive strength. To maintain a mixture satisfactory compressive strength, it is planned to add suitable additives to the cement composite, or to reinforce the blocks by scattered reinforcement [5, 6].

\section{MATERIALS AND SPECIMENS}

A total of 9 sample sets were made, each set containing 3 test specimens. All test samples contained cement and finely ground recycled concrete in ratio $1: 1$. The water ratio $w / c+r$ was 0.32 for all samples. The sets differed in the solidification and hardening accelerator used and its amount. One set was a reference without the use of a solidification and hardening accelerator. To produce samples, Portland cement CEM I 42.5 R from Radotín from the Českomoravský cement company was used. Recycled concrete comes from drainage gutters. A fraction 0/16 mm was used, this material was grinded by the high speed mill. The resulting grain size was under $0.25 \mathrm{~mm}$. The fineness of the ground recycled concrete was similar to the cement, which has a surface area of $361 \mathrm{~m}^{2} / \mathrm{kg}$.

Based on previous works, three types of solidification and hardening accelerators has been selected [7, 8]. Betodur gold (B) is a chloride-free liquid additive that accelerates the hardening of mortars and concretes containing Portland and mixed cements. EKOSAL L (E) is a liquid alkali-free solidification and hardening 


\begin{tabular}{ccccc}
\hline Designation & Product based on & $\begin{array}{c}\text { Normal dosing } \\
{[\text { wt. \% of cement] }}\end{array}$ & $\begin{array}{c}\text { Density } \\
{\left[\mathrm{kg} / \mathrm{m}^{3}\right]}\end{array}$ & $\begin{array}{c}\mathrm{pH} \\
{[-]}\end{array}$ \\
\hline B & Non-chloride liquid & $1.0-3.0$ & $1450 \pm 30$ & $5-7$ \\
E & Non-alkaline liquid & $2.0-8.0$ & $1320 \pm 30$ & $2-4$ \\
S & Polycarboxylates & $0.2-2.5$ & 1050 & 4.5 \\
\hline
\end{tabular}

TABLE 1. Selected hardening accelerators and its properties.

\begin{tabular}{ccccc}
\hline Set / Material & $\begin{array}{c}\text { Micronized } \\
{[\mathrm{g}]}\end{array}$ & $\begin{array}{c}\text { Hardening } \\
\text { accelerator } \\
{[\mathrm{ml}]}\end{array}$ & $\begin{array}{c}\text { Water ratio } \\
w / c+r \\
{[-]}\end{array}$ \\
\hline Ref & 750 & 750 & 0.00 & 0.32 \\
B5 & 750 & 750 & 3.75 & 0.32 \\
B10 & 750 & 750 & 7.50 & 0.32 \\
B15 & 750 & 750 & 11.25 & 0.32 \\
E5 & 750 & 750 & 11.25 & 0.32 \\
E10 & 750 & 750 & 7.50 & 0.32 \\
E15 & 750 & 750 & 11.25 & 0.32 \\
S1 & 750 & 750 & 11.25 & 0.32 \\
S2 & 750 & 750 & 7.50 & 0.32 \\
S3 & 750 & 750 & 11.25 & 0.32 \\
\hline
\end{tabular}

TABLE 2. Composition of the samples.

accelerator that is used primarily for dry-sprayed concrete production. Unlike commonly used hardening accelerators, it is not strongly alkaline and does not adversely affect the environment and workers' health. ViscoCrete 20 Gold (S) is a versatile, highly efficient polycarboxylate-based superplasticizer (PCE), particularly suitable to produce concrete with the requirement of a rapid rise in initial strength (Table 1).

The water ratio was chosen based on previous measurements and hardening accelerator quantities as recommended by the manufacturer. An amount of 5 , 10 and $15 \mathrm{l}$ of setting and hardening accelerator per $\mathrm{m}^{3}$ of mixture was tested (Table 2 ).

For the production of specimens, $40 \times 40 \times 160 \mathrm{~mm}$ laboratory molds were used. The samples were removed from the mold after 6 hours and stored under water in a laboratory environment at a temperature of $21 \pm 2{ }^{\circ} \mathrm{C}$ and a relative humidity of $50 \pm 5 \%$ for 28 days.

\section{EXPERIMENTAL METHODS}

For all samples, the dynamic modulus of elasticity was measured at the age of 7 and 12 hours and subsequently at the age of $1,7,14,21$ and 28 days. A resonance method was used to measure the dynamic modulus of elasticity of samples. Advantage of this method is a speed of measurement and repeatability because it is non-destructive method. The method is based on the calculation of dynamic modulus of elasticity and dynamic shear modulus based on measured fundamental resonance frequencies of longitudinal, transverse (bending) and torsional oscillation. The resonance frequencies were measured in the laboratory using the Brüel \& Kjær measuring system, consisting of the Brüel \& Kjær type 4519-003 response sensor, the Brüel \& Kjær type 8206 impact hammer, the Brüel \& Kjær Front-end 3560B-120 and the control computer. The sample was placed on the supports of sufficiently low stiffness so that the supports were placed at the nodal points of the first waveform corresponding to the given oscillation - longitudinal, transverse or rotational (Fig. 1). The response sensor (S) was attached on the sample to the appropriate position and the oscillation was excited by the impact hammer (B). Both signals, response and excitation were recorded and converted to a frequency domain using a fast Fourier transform. Subsequently, the PULSE LabShop software version 14.0.1 has calculated the transmission function. Based on the resonance peaks in the transmission function, the fundamental resonance frequency of the given oscillation was determined. From the measured resonance frequency, weight, and sample dimensions, the dynamic modulus of elasticity and shear modulus were determined $[9]$. 


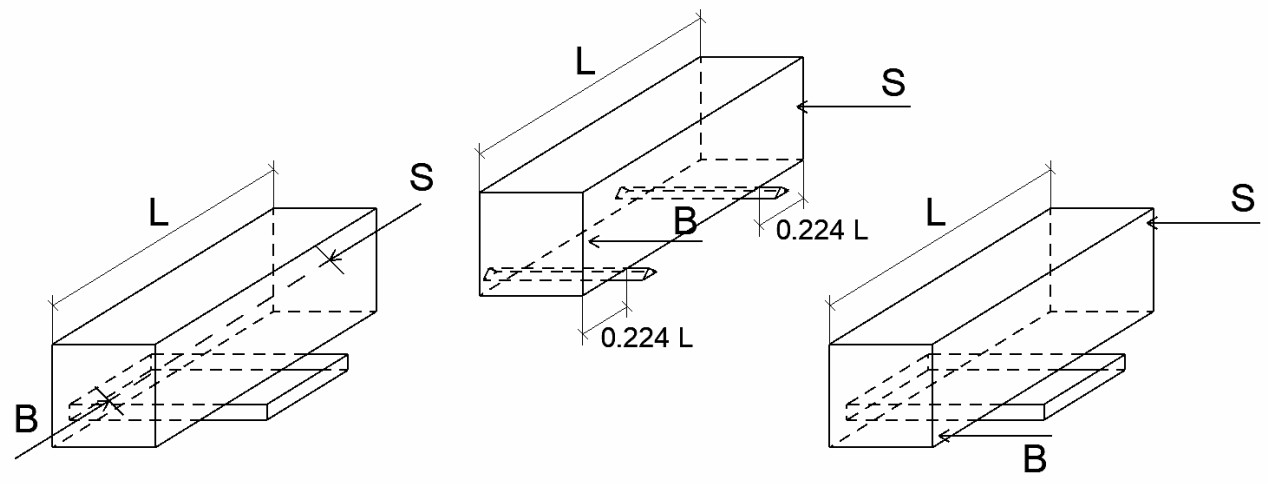

FiguRE 1. Measurement basic natural frequencies from longitudinal (left), transverse (center), and torsional (right) oscillations [10].

\section{Results AND Discussion}

The dynamic modulus of elasticity value of each set was calculated by the arithmetic mean of all 3 samples in the set. Samples were always measured and weighed. The results were calculated on the basis of measured frequencies of longitudinal oscillations (Fig. 2). To verify the correctness of the results, the values of the dynamic modulus of elasticity from the transverse oscillation were calculated too. Moduli of elasticity from the transverse oscillation are almost identical with the values of the moduli of elasticity from the longitudinal oscillation, which confirms the correctness of the measurement. From the growth of the dynamic modulus of elasticity $E_{d y n}$ follows that the maximum increase in $E_{d y n}$ is within the first 7 days. Between 7 and 28 days $E_{d y n}$ growing only slightly.

The rapid increase in the modulus of elasticity in the initial hours is important for the mass production of blocks. The highest increase in the modulus of elasticity after 8 hours was achieved by samples containing accelerator of hardening $B$ (Fig. 3). With the increasing amount of hardening accelerator, the modulus of elasticity also increased, but the increase in the modulus of elasticity from 10 to $15 \mathrm{l} / \mathrm{m}^{3}(7 \%$ modulus increase) was not as pronounced as from 5 to $10 \mathrm{l} / \mathrm{m}^{3}$ (22\% modulus increase). The increase in the modulus of elasticity of B15 samples versus reference samples was $93 \%$. For samples containing the $E$ hardening accelerator, there was only a slight increase in the modulus of elasticity compared to the reference samples $(13 \%)$. We can conclude from the measured values that the modulus of elasticity increased immediately after sample production, which would correspond to the primary purpose of using this hardening accelerator for sprayed concrete.

Samples with $S$ accelerator of hardening could not be removed from the mold at 8 hours after production due to low strength. Samples were removed from the mold after 24 hours.

Measurement of dynamic modulus of elasticity for samples with hardening accelerator in amount of $5 \mathrm{l} / \mathrm{m}^{3}$ was successfully at the age of 24 hours, in amount of 10 and $15 \mathrm{l} / \mathrm{m}^{3}$ at the age of 7 days. For

\begin{tabular}{cc}
\hline Set & $E_{d y n}[\mathrm{GPa}]$ \\
\hline Ref & 1.5 \\
B5 & 2.2 \\
B10 & 2.7 \\
B15 & 2.9 \\
E5 & 1.3 \\
E10 & 1.7 \\
E15 & 1.7 \\
\hline
\end{tabular}

TABLE 3. Modulus of elasticity after 8 hours.

samples $S 2$ and $S 3$ there were a significant decrease in the modulus of elasticity compared to other specimens due to many cracks. The modulus of elasticity after 28 days was approximately the same for all samples, ranging from 20.5 to $20.7 \mathrm{GPa}$, except for $S 2$ and $S 3$ specimens. For $S 2$ samples, the modulus of elasticity decreased by $36 \%$ compared to reference samples and $S 3$ samples decreased by $20 \%$.

\section{Conclusion}

The paper deals with the selection of the most suitable solidification hardening accelerator to produce concrete blocks containing micronized recycled concrete. Three different hardening accelerators $(B, E$ and $S)$ have been selected based on previous measurements and recommendations from manufacturers. To determine the efficiency of the hardening accelerators, the samples were removed from the molds after 6 hours and the dynamic modulus of elasticity was then measured by the resonance method. Based on results, it can be concluded that:

- The greatest increase in the dynamic modulus of elasticity of the mixtures occurs in the first 7 days of hardening. Most then within $24 \mathrm{~h}$.

- As the volume of hardening accelerators increases, the modulus of elasticity also increases, but nonlinearly - a suitable amount of hardening accelerator needs to be determined. 


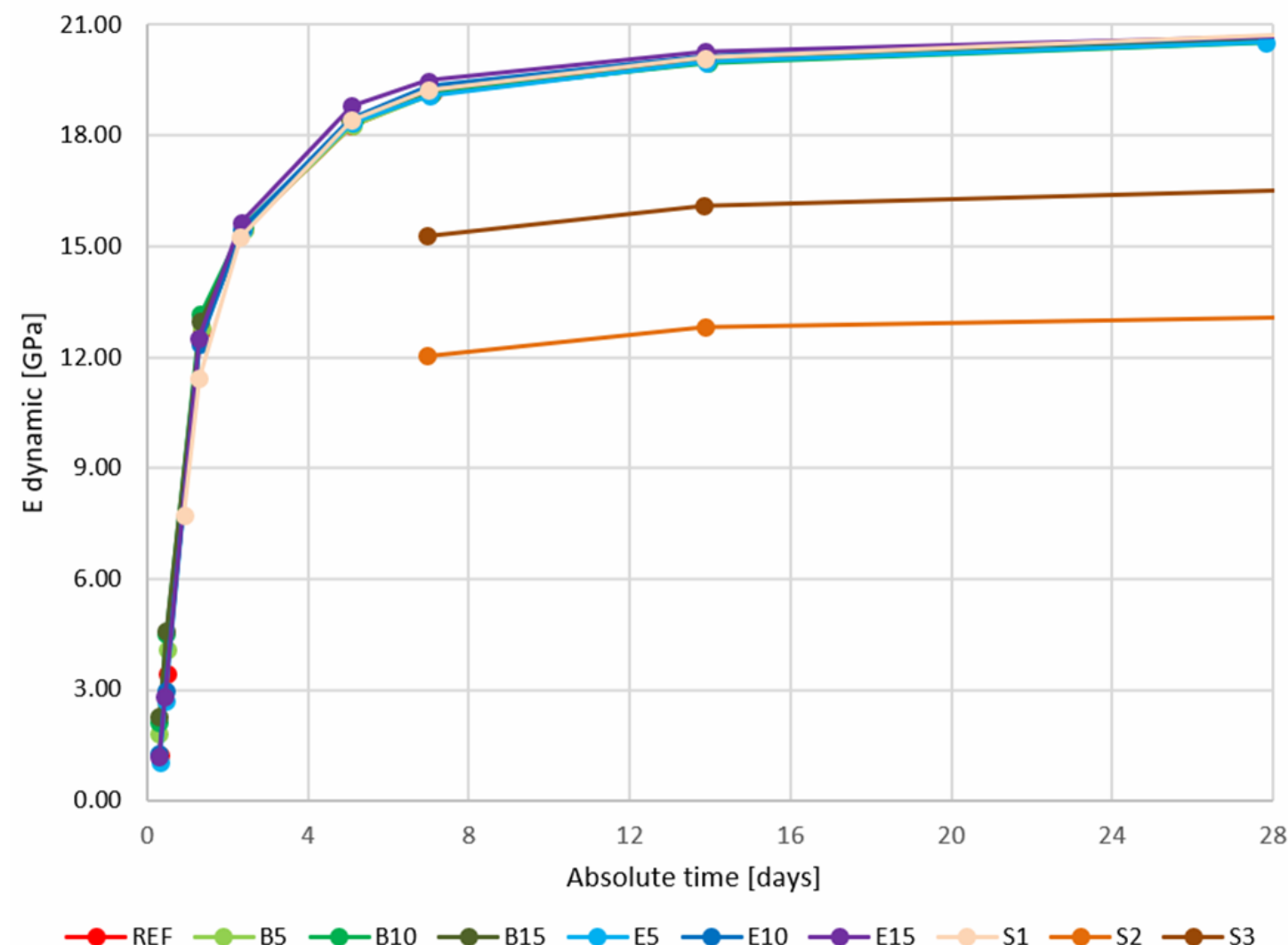

Figure 2. Development of dynamic modulus of elasticity from 0 to 28 days.

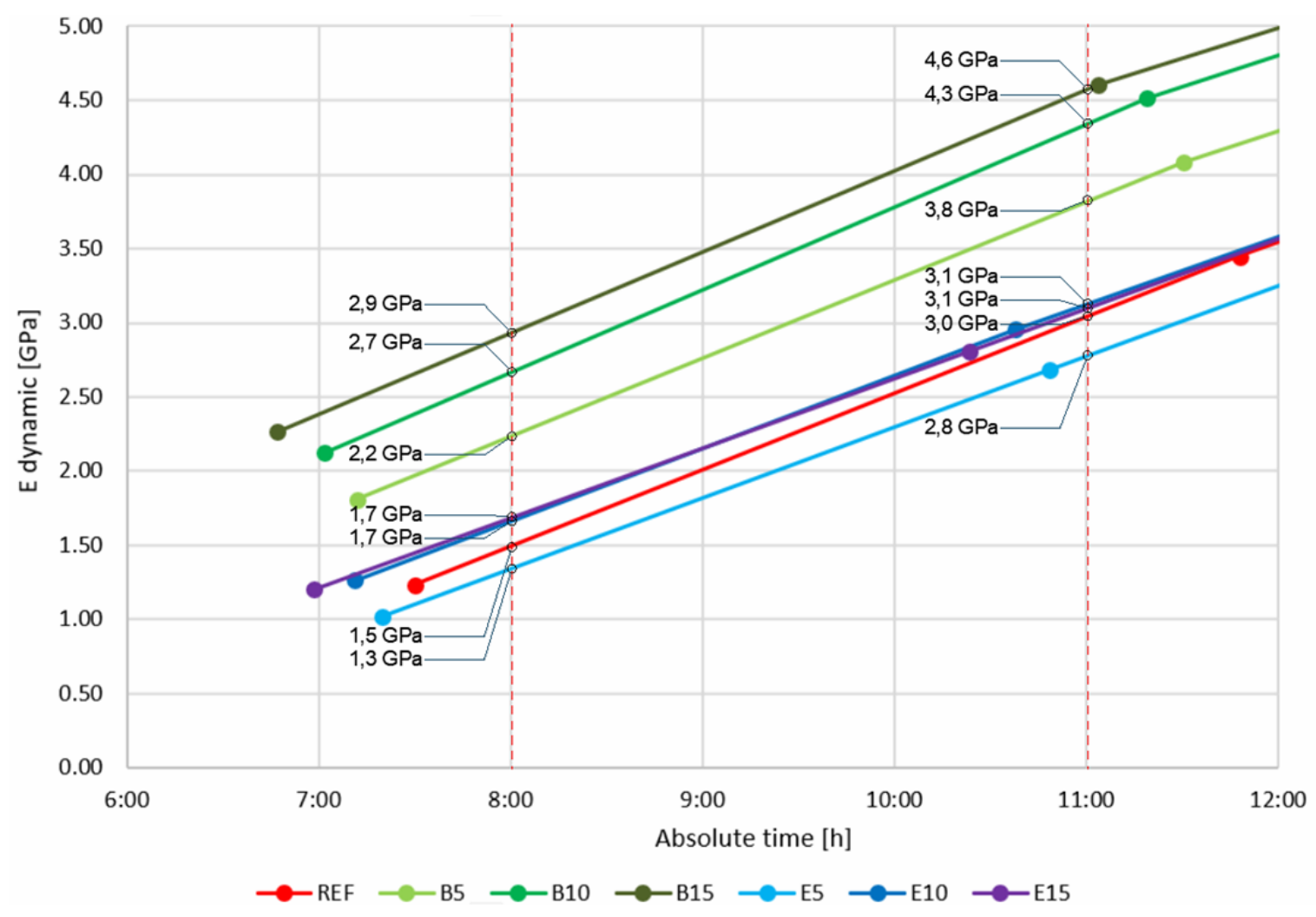

Figure 3. Development of dynamic modulus of elasticity from 7 to 12 hours. 
- Hardening accelerators $B$ and $E$ do not negatively affect the final modulus of elasticity even in the highest used amount.

- The $E$ accelerator of hardening is likely to increase the modulus of elasticity very soon, but it has not been able to achieve sufficient strength for earlier removal from the mold at the used amount.

- Hardening accelerator $S$ proved to be unsuitable, samples were removed from the mold after 24 hours and the modulus of elasticity was lower than for reference samples.

- Hardening accelerator $B$ could be used to increase initial strengths, after 8 hours the samples had almost double modulus of elasticity compared to reference samples.

\section{ACKNOWLEDGEMENTS}

This work was financially supported by the Czech Technical University in Prague - the project SGS16/201/OHK1/3T/11, by the Ministry of Industry and Trade the research project FV20503. The authors also thank to the Center for Nanotechnology in Civil Engineering at the Faculty of Civil Engineering, Czech Technical University in Prague.

\section{REFERENCES}

[1] A. Barbudo, F. Agrela, J. Ayuso, et al. Statistical analysis of recycled aggregates derived from different sources for sub-base applications. Construction and Building Materials 28(1):129-138, 2012. DOI:10.1016/j.conbuildmat.2011.07.035

[2] I. Vegas, J. A. Ibáñez, A. Lisbona, et al. Pre-normative research on the use of mixed recycled aggregates in unbound road sections. Construction and Building Materials 25(5):2674-2682, 2011. DOI:10.1016/j.conbuildmat.2010.12.018.
[3] A. Barbudo, F. Agrela, J. Ayuso, et al. Mechanical properties of recycled binder/micro-filler cement-based material. Construction and Building Materials 1054(1):234-237, 2014. DOI:10.4028/www.scientific.net/AMR.1054.234

[4] M. M. Sabai, M. G. D. M. B. Cox, R. R. Mata, et al. Concrete block production from construction and demolition waste in tanzania. Construction and Building Materials 72(1):9-19, 2013. DOI:10.1016/j.resconrec.2012.12.003

[5] M. Lidmila, J. Topič, T. Plachý, et al. Influence of increasing amount of recycled concrete powder on mechanical properties of cement paste. In IOP Conference Series: Materials Science and Engineering, vol. 236, p. 012094. IOP Publishing, 2017. DOI:10.1088/1757-899X/236/1/012094.

[6] J. Hrůza. Design of masonry elements with use of recycled concrete, 2016

[7] E. Anastasiou, K. G. Filikas, M. Stefanidou. Utilization of fine recycled aggregates in concrete with fly ash and steel slag. Construction and Building Materials 50:154161, 2014. DOI:10.1016/j.conbuildmat.2013.09.037.

[8] F. Cartuxo, J. De Brito, L. Evangelista, et al. Rheological behaviour of concrete made with fine recycled concrete aggregates-influence of the superplasticizer. Construction and Building Materials 89:36-47, 2015. DOI:10.1016/j.conbuildmat.2015.03.119

[9] J. Ďureje, Z. Prošek, J. Hrůza, P. Tesárek. Cement matrix containing micronized recycled concrete and the influence of additives. Acta Polytechnica CTU

Proceedings 15:20-24, 2018. DOI:10.14311/APP.2018.15.0020

[10] ČSN 731372 Nedestruktivní zkoušení betonu-Rezonačnní metoda zkoušení betonu, 2012. 